\title{
The Surface Modification of Tourmaline powder with Acryloyl Chloride and Characterization
}

\author{
Hu Yingmo ${ }^{a}$, Chen Xubo ${ }^{b}$ \\ School of Materials Science and Technology, China University of Geosciences Beijing, 100083, \\ China

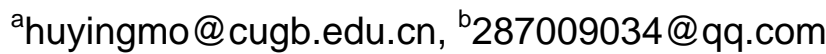

Keywords: acryloyl chloride; surface modification; functional polymer.

\begin{abstract}
The surface modification of the tourmaline powder with acryloyl chloride was studied to prepare the polymerizable organic tourmaline. The experimental results showed that the surface of modified tourmaline had a better hydrophobicity compared with unmodified tourmaline when the mass ratio of acryloyl chloride to tourmaline powder was 3.3:5.0, and reacted $2 \mathrm{~h}$ at $40^{\circ} \mathrm{C}$ in $\mathrm{N}$, $\mathrm{N}$-dimethyl-formamide (DMF). The structure characterization indicated that the acryloyl group has been introduced on the surface of tourmaline powder to get the polymerizable organic tourmaline, and have an excellent far infrared emissivity.
\end{abstract}

\section{Introduction}

Tourmaline is one of type cyclosilicates mineral, the general chemical formula of the tourmaline group can be expressed as $\mathrm{XY}_{3} \mathrm{Z}_{6}\left(\mathrm{~T}_{6} \mathrm{O}_{18}\right)\left(\mathrm{BO}_{3}\right)_{3} \mathrm{~V}_{3} \mathrm{~W}$, where $\mathrm{X}$ sites are mainly occupied by alkaline ions and vacancies, $\mathrm{Y}$ sites are primarily occupied by $\mathrm{Mg}^{2+}, \mathrm{Fe}^{2+}, \mathrm{Mn}^{2+}$, and $\mathrm{Z}$ sites are occupied by trivalent ions of smaller sizes such as $\mathrm{Cr}^{3+}, \mathrm{Al}^{3+}, \mathrm{Fe}^{3+}$ and $\mathrm{V}^{3+}$, a minor amount of other ions such as $\mathrm{Mg}^{2+}$ and $\mathrm{Fe}^{2+}$ can also be found in these sites. T sites are mainly occupied by $\mathrm{Si}^{4+}$ and corner-sharing tetrahedral form hexagonal rings, $\mathrm{V}$ sites are mainly occupied by $\mathrm{O}^{2-}$ and $\mathrm{OH}^{-}$; and $\mathrm{W}$ sites are occupied by $\mathrm{O}^{2-}, \mathrm{OH}^{-}$, and $\mathrm{F}^{-}$. Depending on different isomorphism states, the tourmaline group can be divided into schorl, dravite and elbaite[1]. The complex crystal structures of tourmaline lead to various characteristics, such as permanently spontaneous polarization [2], thermoelectricity [3] and piezoelectricity [4]. When the environmental temperature or pressure of tourmaline changes, relative displacement will occur among intracrystal electric particles of tourmaline, resulting in a potential difference and ionizing the surrounding air the generated negative charges can be delivered to the dust and smoke particles, to achieve the purpose of air purification [5]. Tourmaline crystals present dipole distance, when the temperature rises, the polar ions in the crystals will move due to thermal agitation and cause dipolar moment changes, and the excess energy will be released in the form of electromagnetic waves. The engendered far infrared ray can be absorbed by the human body, and promote blood microcirculation, benefiting the health conditions of human bodies [6,7]. Therefore, if tourmaline could composite with polymer fibers to prepare the functional composite materials, it was favored of comprehensive utilization of tourmaline and development of functional composites.

However, the compatibilities between tourmaline and organic matrix are very poor, the mechanical performance of the composites could not be satisfied with its application [8]. In order to improve the compatibility of tourmaline and the polymer matrix, surface modification of tourmaline by organic species were tried to study by researchers in recent years [9-14].

In order to develop the functional polymer containing tourmaline, the surface modification of the tourmaline powder with acryloyl chloride was studied in this work to synthesize the polymerizable organic tourmaline, the optimized process was investigated with the experimental parameters of contact angles and turbidities of modified tourmaline, and the structure of the modified tourmaline was characterized by XRD, IR and SEM. 


\section{Experimental and Materials}

Materials. Tourmaline powder $\left(\mathrm{TM}, \mathrm{d}_{50}=1.75 \mu \mathrm{m}, \mathrm{d}_{97}=5.23 \mu \mathrm{m}\right)$ was obtained from Yanxin Mineral Co. Ltd., Hebei, China; N, N-dimethylformamide (DMF, CP,_Xilong Chemical Co., Ltd., Shantou, China) was dehydrated by anhydrous sodium sulfate, acryloyl chloride (CP, Huateng Technology Co., Ltd., Beijing, China), sulfuric acid (CP, Beijing Chemical Works, Beijing, China), anhydrous alcohol (CP, Beijing Chemical Works, Beijing, China), and liquid paraffin(CP, Tianjin Fucheng Chemical Works, Tianjin, China) were used as original.

Acryloyl chloride modified tourmaline. In a $100 \mathrm{~mL}$ four-neck flask equipped with condenser, funnel, thermometer and electromagnetic stirrer, 5 gram of tourmaline powder was dispersed in 15 $\mathrm{mL}$ dried DMF, and heated to $40^{\circ} \mathrm{C}$ with sufficient stirring, $0.1 \mathrm{~mL}$ sulfuric acid was added into flask, and $3.0 \mathrm{~mL}$ acryloyl chloride was dropped into the flask with funnel, the mixture was stirred $3 \mathrm{~h}$ at $40^{\circ} \mathrm{C}$. The samples were separated by filtration with vacuum, then washed three times with anhydrous ethanol, and finally dried and grinded to be characterized.

The determination of turbidity. 1.0gram of modified tourmaline powder was added into a 100 $\mathrm{ml}$ beaker with $50 \mathrm{ml}$ liquid paraffin. The mixture was stirred for 5 minutes and let to stand for 24h. Then, the supernatant liquid was collected to test its turbidity by SGZ-2 nephelomete

The measurement of contact angle. The sample was pressed into circle by presser, and then the distilled water was dropped on the surface of pressed sample to evaluate the contact angle by DSA100M optical measure, with each value averaged over three tests.

\section{Results and discussion}

The modified effect of tourmaline powder with acryloyl chloride under various conditions were studied by focusing on the experimental parameters of turbidity in liquid paraffin and contact angles under different experimental conditions, and the structure of modified tourmaline was characterized.

Effect of reaction temperature. The curves of contact angle and turbidity of modified tourmaline with reaction temperature were shown in figure 1 . Both contact angle and turbidity of modified tourmaline increased with the rising of reaction temperature below $40^{\circ} \mathrm{C}$, then reduced with the persistent rising of reaction temperature, and had the maximum at $40^{\circ} \mathrm{C}$.

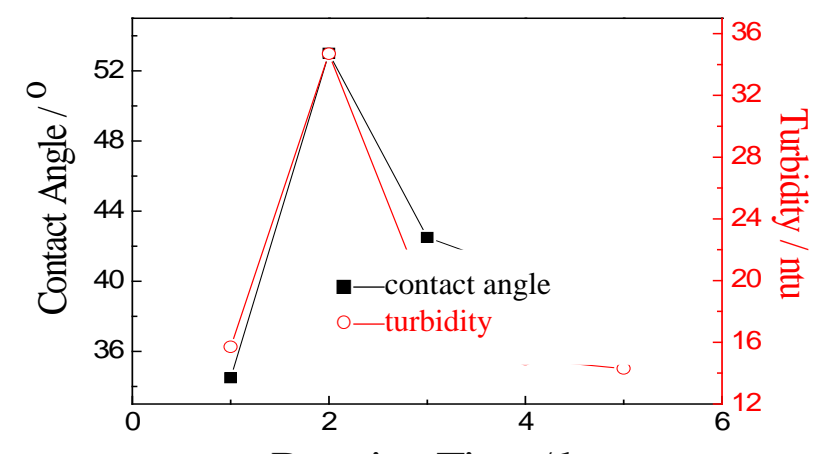

Figure 1. Effect of reaction temperature

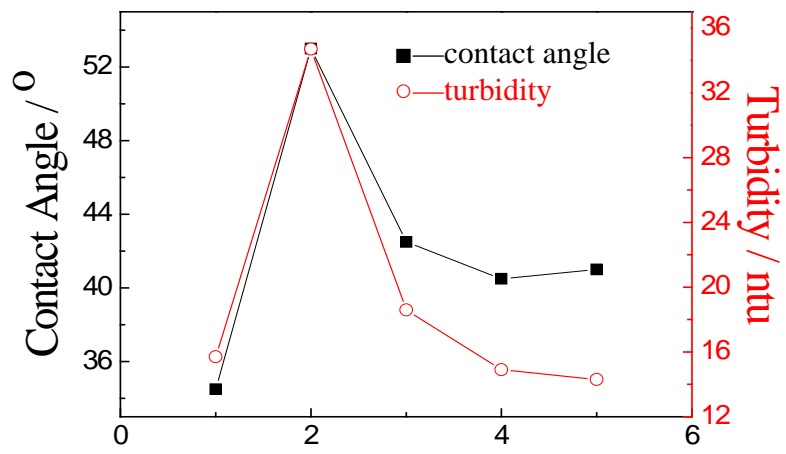

Figure 2. Effect of reaction time

Effect of reaction time. Figure 2 revealed the influence of reaction time on the contact angle and turbidity of modified tourmaline. Figure 2 shown the same trend on contact angle and turbidity of modified tourmaline that increased sharply with the prolonging of reaction time at first, and decreasing clearly with continuous increasing of reaction time, the optimal reaction time was $2 \mathrm{~h}$.

Effect of the dosage of tourmaline. By fixing the dosage of solvent (DMF) as $50 \mathrm{~mL}$, the effect of the amount of tourmaline on contact angle and turbidity of modified tourmaline were shown in figure 3, The contact angle and turbidity of modified tourmaline tended to increase with the increasing of tourmaline, and trend to decrease when the amount of tourmaline were over $5 \mathrm{~g}$. Accordingly, the optimal amount of tourmaline was $5 \mathrm{~g}$ in this work. 


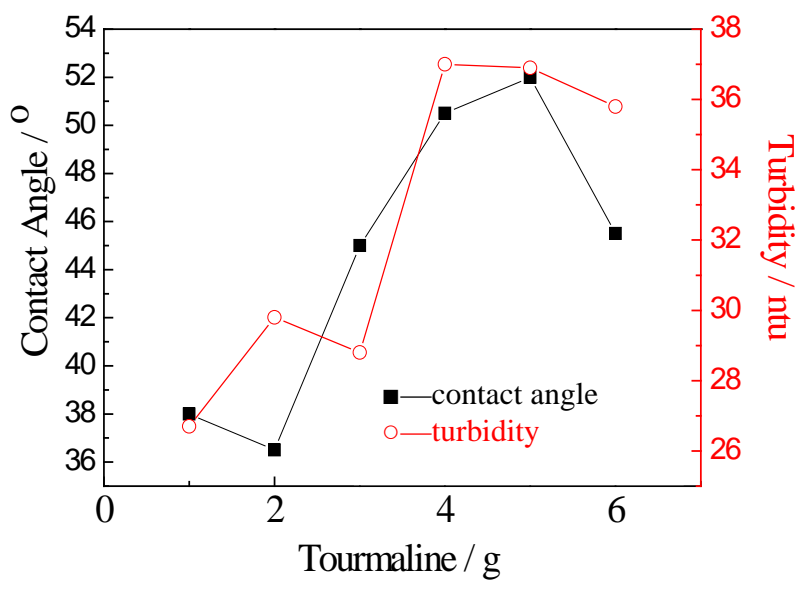

Figure 3. Effect of the amount of tourmaline

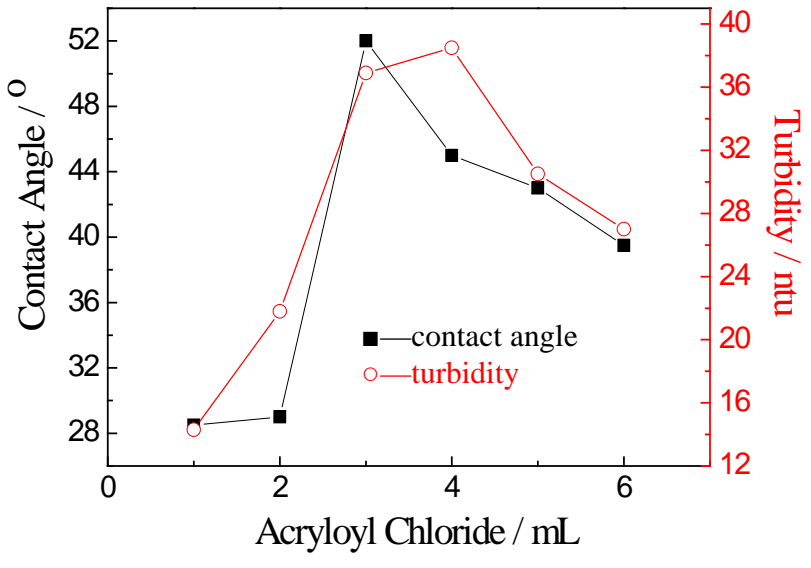

Figure 4. Effect of acryloyl chloride

Effect of acryloyl chloride. The effect of acryloyl chloride on turbidity and contact angle of modified tourmaline were exhibited in figure 4. The turbidity and contact angle of modified tourmaline increased speedly with the increasing of acryloyl chloride at beginning, then reduced with further increasing of acryloyl chloride when the dosage of acryloyl chloride was over $3 \mathrm{~mL}$, and have the optimum at $3 \mathrm{~mL}$ of acryloyl chloride.

IR analysis. The IR spectra of unmodified tourmaline and modified tourmaline were shown in figure 5. In figure 5a, unmodified tourmaline [14] have absorption bands at $3558 \mathrm{~cm}^{-1}$ (-OH group), $1272 \mathrm{~cm}^{-1}$ (B-O group) and $975 \mathrm{~cm}^{-1}$ (Si-O group), and the IR spectrum of modified tourmaline (Figure 5b) shows that absorption bands of methyl $\left(2923 \mathrm{~cm}^{-1}\right)$, methylene $\left(2853 \mathrm{~cm}^{-1}\right)$, carbonyl $\left(1720 \mathrm{~cm}^{-1}\right)$ and double bond $\left(1630 \mathrm{~cm}^{-1}\right)$ of acryloyl group have appeared, besides those, the absorption shape of tourmaline almost unchange clearly but all wavelengths shift corresponding to unmodified tourmaline owing to the electronic effect of acryloyl group. This indicats that acryloyl group has been introduced in the surface of tourmaline to get polymerizable tourmaline acrylate.

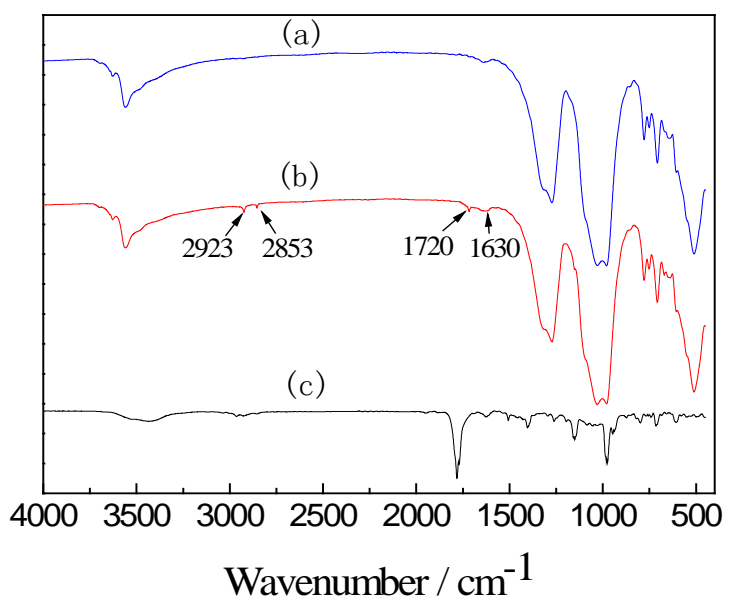

Figure 5. FT-IR spectra of tourmaline(a), modified tourmaline(b), acryloyl chloride(c)

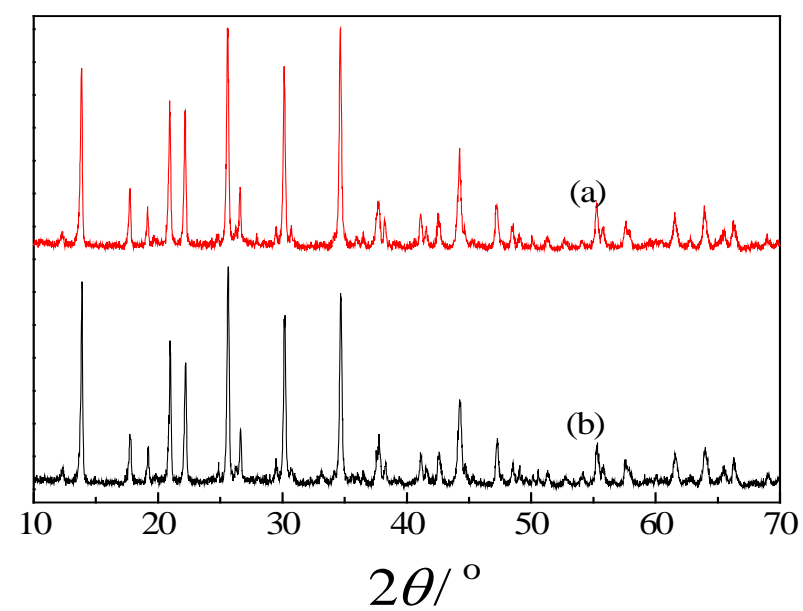

Figure 6. XRD of (a) tourmaline and (b) modified tourmaline

XRD patterns. XRD spectra of unmodified and modified tourmaline are shown in Figure 6. The major peaks of unmodified tourmaline (Figure $6 \mathrm{a}$ ) are observed at $2 \theta$ of $13.8^{\circ}, 21.0^{\circ}, 22.0^{\circ}, 25.5^{\circ}$, $26.7^{\circ}, 30.3^{\circ}, 34.7^{\circ}, 44.3^{\circ}, 47.1^{\circ}, 55.3^{\circ}, 57.7^{\circ}, 61.5^{\circ}, 63.9^{\circ}$, while the major peaks of modified tourmaline locate at the same $2 \theta$ and no other phases are detected. The two nearly identical spectra indicate that the introductions of acryloyl group do not alter tourmaline's crystal structure. 
SEM images. Figure 7 shows the SEM images of unmodified and modified tourmaline. Some conglomeration in unmodified tourmaline particles was apparent (Figure 7a), and no agglomerates were observed in modified tourmaline particles (Figure $7 \mathrm{~b}$ ). These results are attributable to the strong polar surfaces of tourmaline particles before modification facilitated the easy conglomeration of the particles. And the surface polarity of the tourmaline decreased after the organic modification, the surface energy was depressed, therefore the dispersivity of the tourmaline particles was improved obviously.

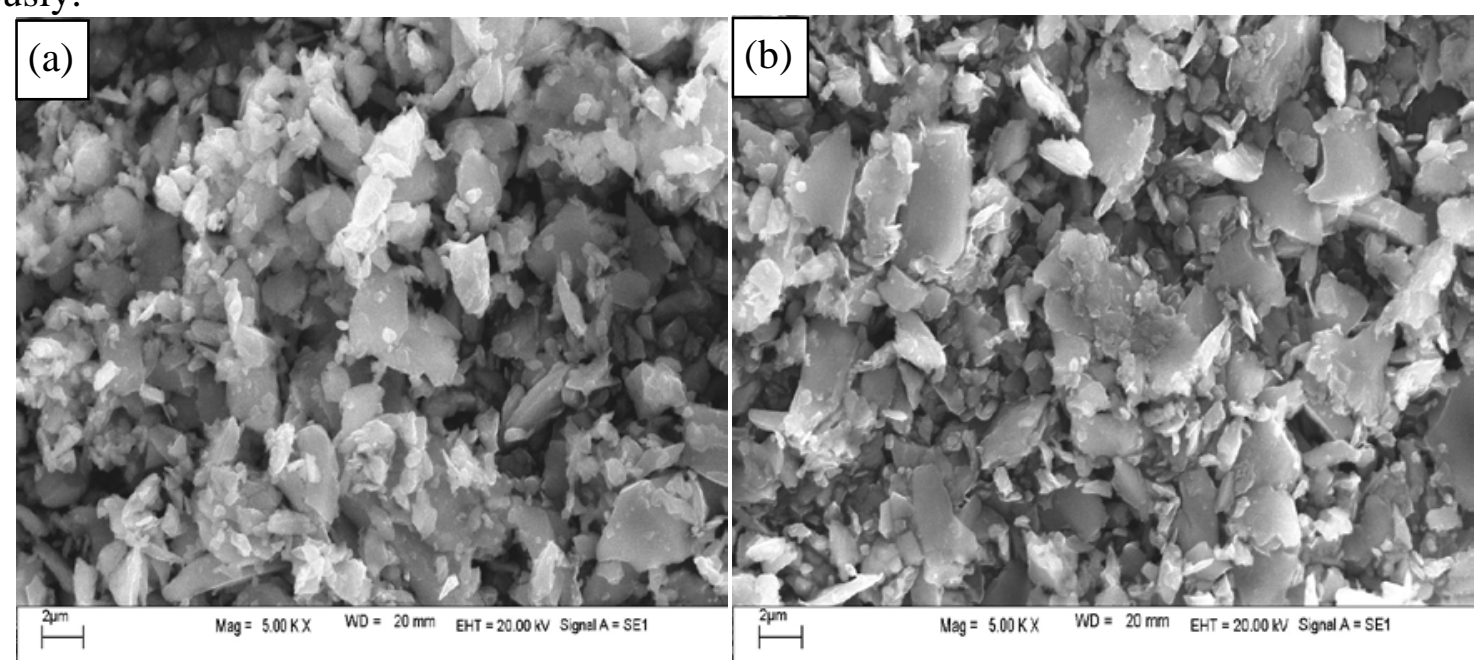

Figure 7. SEM images of tourmaline(a) and modified tourmaline (b)

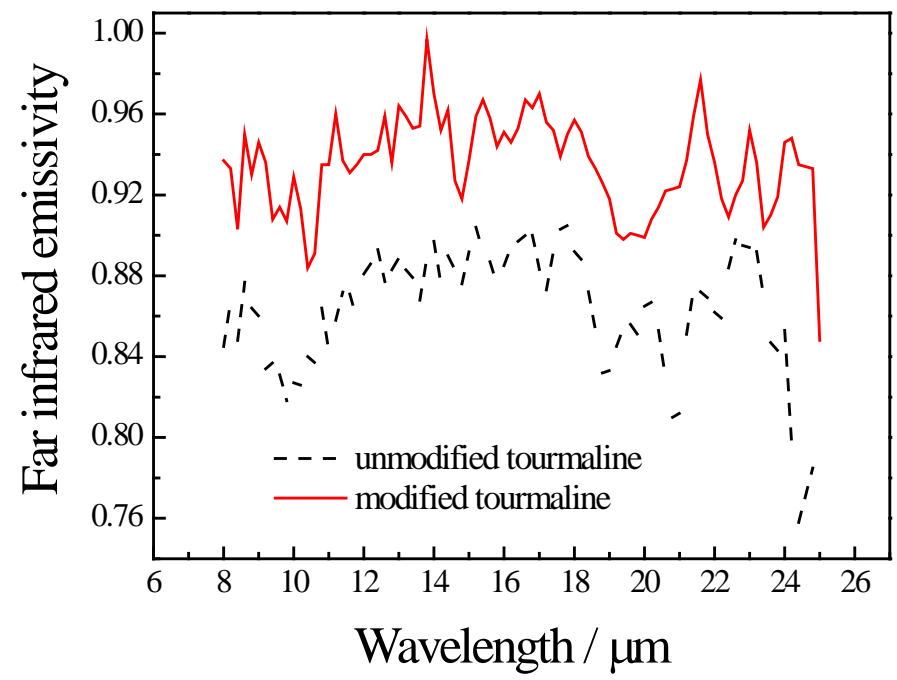

Figure 8. Far infrared emissivity of unmodified and modified tourmaline

Far-infrared radiation analysis. The far infrared emissivity of modified and unmodified tourmaline was measured over $8 \sim 25 \mu \mathrm{m}$ wavelength range at $100^{\circ} \mathrm{C}$, and showed in Figure 8 . In contrast, the modified tourmaline possessed higher far infrared emissivity than unmodified tourmaline due to its lower polarity, higher dispersion and surface areas after modification [15].

\section{Summary}

The surface modification of tourmaline with acryloyl chloride was investigated, and optimized the modified conditions with parameters of the turbidity and contact angle of modified tourmaline. The experimental results showed that the modified tourmaline with acryloyl chloride had a better hydrophobicity compared with unmodified tourmaline when the mass ratio of acryloyl chloride to tourmaline powder was 3.3:5.0, and reacted $2 \mathrm{~h}$ at $40{ }^{\circ} \mathrm{C}$ in $\mathrm{N}, \mathrm{N}$-dimethylformamide (DMF). The IR spectra revealed that acryloyl group has been introduced in the surface of tourmaline to get 
polymerizable tourmaline acrylate, and the modified tourmaline kept the same crystal structures as the unmodified one, and have an excellent far infrared emissivity. This work offered the base data for the synthesis of functional polymers, the investigation of tourmaline-containing functional polymer is under way yet.

\section{Acknowledgment}

This work is supported by the National Natural Science Foundation of China (No.51372233).

\section{References}

[1] L.Zhang, Y.Wu, B.Xiao, Research on the Composition, Structure and Deep Processing Technology of Tourmaline. Multipurpose Utilization of Mineral Resources, 4 (2009) 30-34.

[2] T.Kubo, Interface Activity of Water Given Rise by Tourmaline. Solid State Physics, 24 (1989) 1055-1060.

[3] J.Wei, Y.Y.Liu, K.Y.Zhang, Study on Application Features of Tourmaline. Non-Metallic Mines, 26 (2003) 34-36.

[4] X.F.Zhang, R.H.Wu, Y.Dong, Research on Surface Electricity Propriety of Tourmaline Powder. China Mining Maganize, 14 (2005) 73-76.

[5] W.W.Li, R.H.Wu, Y.Dong, Study on Infrared Spectra and Infrared Radiation Characteristics of Tourmaline. Geological Journal of China Universities, 14 (2008) 426-432.

[6] G.M.Garda, R.B.Trumbull, P.Beljavskis, Boron isotope composition of tourmalines and vein tourmalines associated with gold mineralization, Serra do Itaberaba Group, central Ribera Belt, SE Brazil. Chemical Geology, 264 (2009) 207-220.

[7] B.J.Reddy, R.L.Frost, W.N.Martens, Spectroscopic characterization of Mn-rich tourmalines. Vibrational Spectroscopy, 44 (2007) 42-49.

[8] Y.Song, W.Han, J.Z.Chen, Influence of its Granularity in Preparation of Ultra-fine Tourmaline. Conservation and Utilization of Mineral Resources, 1 (2005) 13-16.

[9] T.Masahiro, T.Z.Hussein, K.Yoshinori, Modeling of an external light irradiation slurry photo-reaction: UV light or sunlight-photo assisted Fenton discoloration of azo-dye O range II with natural mineral tourmaline powder. Chemical Engineering Science, 61 (2006) 6361-6371.

[10] X.Yang, Y.M.Hu, Y.Liu, Recent Developments of Tourmaline Powder Surface Modification. China Non-metallic Mining Industry Herald, 6 (2010) 18-21.

[11] J.Bian, Y.M.Hu, X.Yang, Structure Characterization and Surface Modification of Tourmaline Powder with Lauroyl Chloride. Bulletin of the Chinese Ceramic Society, 30 (2011) 1-5.

[12] Y.M.Hu, P.Xiong, X.Yang, Aluminic Ester Modified Tourmaline Powder and Characterization. Geological Journal of China Universities, 17 (2011) 447-451.

[13] J.H.Darrell, K.B.Milka, Mineral chemistry and chemical zoning in tourmalines, Pampa del Tamboreo, San Luis, Argentina. Journal of South American Earth Sciences, 28 (2009) 132-141.

[14] P. S. R.Prasad, D. S.Sarma, Study of structural disorder in natural tourmaline by infrared spectroscopy. Gondwana Research, 8 (2005) 265-270.

[15] F.Ren, Study on Infrared Radiation Properties of Tourmaline Powder. Non-Metallic Mines, 35 (2012) 43-45. 